\title{
Myoglobin as a Prognostic Factor in Trauma Patients
}

\author{
Ji Woong Yeom, M.D., Oh Hyun Park, M.D., Yun Chul Park, M.D., \\ Wu Seong Kang, M.D., Jung Chul Kim, M.D. \\ Division of Trauma Surgery, Department of Surgery, \\ Chonnam National University Medical School, Gwangju, Korea
}

Correspondence to:
Jung Chul Kim, M.D.
Department of Surgery,
Chonnam National University
Hospital, 42 Jebong-ro,
Dong-gu, Gwangju 501-757,
Korea
Tel: +82-62-220-6456
Fax: +82-62-227-1635
E-mail: 3rdvivace@hanmail.net
Purpose: To describe the association of serum myoglobin and creatine kinase (CK) with prognosis in trauma patients.

Methods: We evaluated 108 trauma patients older than age 15 years who received treatment in the Department of Trauma Surgery from January 2012 to December 2012. Myoglobin and CK serum levels were measured during the week after injury.

Results: The average age of the 108 patients ( 80 [74.1\%] men and 28 [25.9\%] women) was 49.8 years. Sixteen $(14.8 \%)$ developed complications and eight $(50.0 \%)$ developed acute kidney injury (AKI). All patients with AKI underwent hemodialysis, and six died. Higher serum levels of myoglobin and CK were associated with AKI. Twelve patients died during the study period, and myoglobin and CK serum levels were higher in non-survivors. Of these two factors, myoglobin serum level was independently predictive of death.

Conclusion: In trauma patients, higher serum levels of myoglobin and CK were found to be associated with AKI and death. Higher serum levels of myoglobin were influential for predicting death. (J Acute Care Surg 2014;4:73-78)

Key Words: Wounds and injuries, Myoglobin, Creatine kinase, Acute kidney injury

Received August 14, 2014, Revised October 1, 2014, Accepted October 1, 2014

Copyright (c) 2014 by Korean Society of Acute Care Surgery

(c) This is an Open Access article distributed under the terms of the Creative Commons Attribution Non-Commercial License (http://creativecommons.org/licenses/by-nc/3.0) which permits unrestricted non-commercial use, distribution, and reproduction in any medium, provided the original work is properly cited.

ISSN 2288-5862(Print), ISSN 2288-9582(Online)

\section{Introduction}

Myoglobin reversibly combines with oxygen and stores oxygen primarily in muscle tissue [1]. Myoglobin is released into the blood and undergoes metabolic change when muscular tissue is damaged, which affects renal epithelial cells, and causes acute kidney injury (AKI) [2,3]. Creatine kinase (CK) is an enzyme found in cells, and is used to convert adenosine triphosphate into adenosine diphosphate. $\mathrm{CK}$ is found particularly in skeletal muscle.

Muscular damage-related factors usually measure higher than normal in trauma patients but this depends on trauma severity. About $3 \sim 15 \%$ of patients with atraumatic rhabdomyolysis and
$30 \%$ of patients with traumatic rhabdomyolysis show increased serum levels of myoglobin and CK and develop AKI [3].

Many researchers have conducted studies on prognostic factors of trauma patients, but there are few direct studies about AKI and death in association with serum levels of myoglobin and CK.

Therefore, we investigated the serum levels of myoglobin and CK in trauma patients and their utility as prognostic factors for predicting mortality.

\section{Methods}

A total of 108 trauma patients older than 15 years, who 
received hospital treatment for trauma at Chonnam National University Hospital from January 2012 to December in 2012, was included. Patients who died in 24 hours were excluded. An emergency exploratory laparotomy, interventional procedures, or conservative treatment were provided according to the patient's vital signs and test results. The serum levels of myoglobin and CK were measured every 24 hour until which were normalized. The normal range of myoglobin and CK was 10.2 to $92.5 \mathrm{ng} / \mathrm{ml}$ and 35 to $172 \mathrm{U} / \mathrm{L}$ respectively. AKI was diagnosed by the risk, injury, failure, loss, end-stage renal disease criteria and all of patients with AKI received continuous renal replacement therapy [4,5]. All patients were observed for demographic data, transfusion, Injury Severity Score (ISS), complications, and clinical outcomes.

We compared the patients who developed AKI with the other patients. In addition, a comparative analysis of clinical factors was conducted about mortality by dividing the patients into non- survivor and survivor groups. Student's t-test, the Mann-Whitney U-test, Fisher's exact test, receiver operating characteristic (ROC) curves, and a logistic regression were conducted using IBM SPSS Statistics ver. 19.0 (IBM Co., Armonk, NY, USA). Variables with a statistical $\mathrm{p}<0.20$ in a univariate analysis were entered into a multivariate analysis, and $\mathrm{p}<0.05$ were considered significant.

\section{Results}

\section{Clinical Characteristics of the Patients}

Demographics and clinical characteristics of the patients were outlined in Table 1. The average age of the 108 patients was 49.8 years (80 men [74.1\%] and 28 [25.9\%] women). The average hospitalization was 16.4 days and the average hospitalization in the intensive care unit (ICU) was 3.7 days. Ninety-seven (89.8\%) patients had blunt injuries, and 11 (10.2\%) had penetrating injuries. An emergency exploratory laparotomy was conducted in 63 (58.3\%) patients and conservative treatment was provided for 45 (41.7\%); 12 of the 45 patients $(26.7 \%)$ received an interventional procedure. A total number of $16(14.8 \%)$ patients developed a complication; eight of them had AKI and eight had a pancreatic pseudocyst, intraperitoneal infection, or delayed bowel perforation. All eight patients with AKI underwent hemodialysis and six died. A total number of 12 patients died during treatment. Among them, nine patients received an emergency exploratory laparotomy, and three received an interventional procedure.

\section{Comparisons between the Non-AKI Group and AKI Group}

We summarized the results about comparisons between the non-AKI group and AKI group in Table 2. Age, red blood cell (RBC) transfusion volume, ICU length of stay in the AKI group were higher than those in the non-AKI group. Especially, for most of seven days after damage, serum levels of myoglobin in the AKI group were significantly higher than those in the non-AKI group. CK concentrations were higher than non-AKI group for all days; however, it was statistically significant on 5 th and 7 th day after damage.

Table 1. Patient clinical characteristics

\begin{tabular}{lc}
\multicolumn{1}{c}{ Characteristic } & Total $(\mathrm{n}=108)$ \\
\hline Gender & \\
Male & $80(74.1)$ \\
Female & $28(25.9)$ \\
Age in years & $49.8 \pm 16.4$ \\
Injury mechanism & \\
Blunt & $97(89.8)$ \\
Penetrating & $11(10.2)$ \\
Hospital stay in days & $16.4 \pm 11.5$ \\
Intensive care unit stay in days & $3.7 \pm 8.0$ \\
Injury Severity Score & $15.5 \pm 9.2$ \\
Management & \\
Operation & $63(58.3)$ \\
Nonoperative & $45(41.7)$ \\
Intervention/conservative & $(26.7) / 33(73.3)$ \\
Complications & $16(14.8)$ \\
Acute kidney injury & $8(50.0)$ \\
Pancreatic pseudocyst & $3(18.8)$ \\
Infection & $12(6.2)$ \\
Hepatic aneurysm & $1(6.2)$ \\
Small bowel necrosis & $1(6.2)$ \\
Perihepatic abscess & $2(12.6)$ \\
Mortality & $12.1)$ \\
\hline
\end{tabular}

Values are presented as number (\%) or mean \pm standard deviation. 
Table 2. Comparisons between the non-AKI and AKI groups

\begin{tabular}{|c|c|c|c|}
\hline & Non-AKI $(n=100)$ & $\mathrm{AKI} \quad(\mathrm{n}=8)$ & $\mathrm{p}$-value \\
\hline Age (y) & $48.7 \pm 16.2$ & $63.3 \pm 13.3$ & 0.015 \\
\hline Gender & & & 0.677 \\
\hline Male & $73(73.0)$ & $7(87.5)$ & \\
\hline Female & $27(27.0)$ & $1(12.5)$ & \\
\hline Injury Severity Score & $15.0 \pm 8.5$ & $22.5 \pm 14.1$ & 0.178 \\
\hline \multicolumn{4}{|l|}{ Myoglobin $(\mu \mathrm{g} / \mathrm{ml})$} \\
\hline Day 1 & $620.0 \pm 1,326.5$ & $7,136.0 \pm 9,941.0$ & 0.106 \\
\hline Day 2 & $490.0 \pm 1,585.9$ & $8,874.0 \pm 10,058.0$ & $<0.001$ \\
\hline Day 3 & $468.7 \pm 2,446.3$ & $10,088.0 \pm 14,788.8$ & $<0.001$ \\
\hline Day 5 & $138.7 \pm 288.6$ & $3,251.4 \pm 3,108.0$ & $<0.001$ \\
\hline Day 7 & $219.8 \pm 703.0$ & $2,111.6 \pm 2,780.3$ & $<0.001$ \\
\hline Peak & $824.5 \pm 2,491.7$ & $13,102.6 \pm 14,926.5$ & $<0.001$ \\
\hline \multicolumn{4}{|l|}{ Creatine kinase $(\mathrm{U} / \mathrm{L})$} \\
\hline Day 1 & $894.5 \pm 1,088.7$ & $2,429.3 \pm 3,589.3$ & 0.236 \\
\hline Day 2 & $1,137.4 \pm 1,062.8$ & $4,867.4 \pm 8,035.3$ & 0.791 \\
\hline Day 3 & $1,235.9 \pm 2,714.6$ & $5,091.3 \pm 5,324.9$ & 0.066 \\
\hline Day 5 & $1,009.3 \pm 3,193.0$ & $2,139.0 \pm 2,328.9$ & 0.013 \\
\hline Day 7 & $1,202.3 \pm 4,390.6$ & $1,305.2 \pm 945.5$ & 0.023 \\
\hline Peak & $1,579.4 \pm 2,491.7$ & $5,628.5 \pm 7,434.0$ & 0.062 \\
\hline Red blood cell transfusion (U) & $3.1 \pm 4.7$ & $12.3 \pm 17.0$ & 0.031 \\
\hline Intensive care unit stay (d) & $2.3 \pm 4.5$ & $21.6 \pm 10.8$ & $<0.001$ \\
\hline Serum lactate (mmol/L) & $3.6 \pm 3.6$ & $7.6 \pm 7.2$ & 0.052 \\
\hline
\end{tabular}

Values are presented as mean \pm standard deviation or number $(\%)$.

AKI: acute kidney injury.

\section{Comparisons between Survivors and Non-survivors}

We showed the results about comparisons between survivors and non-survivors in Table 3. Age, ISS, RBC transfusion volume, ICU length of stay, blood lactic acid contents of non-survivors were significantly higher than those of survivors. All Serum levels of myoglobin were significantly higher in non-survivors than those of survivors. CK tended to be higher in non-survivors than those of survivors over one week of treatment. However, they were significant only on 3th, 5th and 7 th day after damage.

\section{Independent Predictors for Mortality by a Multivar-} iate Logistic Regression Analysis

We conducted a multivariate logistic analysis using log myoglobin values, as the difference between the maximum and minimum serum myoglobin values was too large, and they were not normally distributed. Regarding other factors, serum myoglobin peak value in non-survivors was influential factor $(\mathrm{p}=0.041$; odds ratio, 2.6; Table 4).

ROC Curve for Serum Myoglobin, Lactate, CK in Predicting Death

With respect to prediction of the death, ROC statistics revelaed the area under the curve of 0.94 for the peak myoglobin levels, 0.74 for the peak CK levels, 0.77 for lactate. A cut off value of serial peak myoglobin was $3,510 \mathrm{ng} / \mathrm{ml}$. Sensitivity was $89 \%$ and specificity was $98 \%$, respectively (Fig. 1).

\section{Discussion}

Myoglobin, which is a causal factor for AKI, occurs more in muscle and is released into the blood when muscle is damaged [1]. Then, myoglobin undergoes a metabolic change and causes renal damage [6]. CK is an enzyme that occurs in many tissues and cells. An increase of CK in the blood is related to muscle damage such as rhabdomyolysis, acute 
Table 3. Comparisons between survivors and non-survivors

\begin{tabular}{|c|c|c|c|}
\hline & Survivors $(\mathrm{n}=96)$ & Non-survivors $(\mathrm{n}=12)$ & p-value \\
\hline Age (y) & $47.7 \pm 15.7$ & $66.7 \pm 11.5$ & $<0.001$ \\
\hline Gender & & & 0.504 \\
\hline Male & $72(90.0)$ & $8(10.0)$ & \\
\hline Female & $24(85.7)$ & $4(14.3)$ & \\
\hline Injury Severity Score & $14.1 \pm 7.4$ & $27.0 \pm 13.3$ & 0.001 \\
\hline \multicolumn{4}{|l|}{ Myoglobin $(\mu \mathrm{g} / \mathrm{ml})$} \\
\hline Day 1 & $1,335.1 \pm 4,730.2$ & $3,561.0 \pm 3,206.4$ & $<0.001$ \\
\hline Day 2 & $1,116.0 \pm 4,590.0$ & $5,190.0 \pm 4,807.5$ & $<0.001$ \\
\hline Day 3 & $568.2 \pm 2,161.7$ & $9,491.8 \pm 16,071.4$ & $<0.001$ \\
\hline Day 5 & $269.6 \pm 617.7$ & $3,161.7 \pm 3,448.7$ & $<0.001$ \\
\hline Day 7 & $180.3 \pm 364.8$ & $2,817.0 \pm 3,056.0$ & $<0.001$ \\
\hline Peak & $801.3 \pm 3,300.2$ & $11,960.1 \pm 12,538.6$ & $<0.001$ \\
\hline \multicolumn{4}{|l|}{ Creatine kinase $(\mathrm{U} / \mathrm{L})$} \\
\hline Day 1 & $1,164.0 \pm 1,273.0$ & $1,579.3 \pm 2,006.8$ & 0.584 \\
\hline Day 2 & $1,305.3 \pm 1,200.1$ & $2,332.8 \pm 3,835.9$ & 0.681 \\
\hline Day 3 & $1,465.5 \pm 3,272.8$ & $3,593.0 \pm 4,608.2$ & 0.022 \\
\hline Day 4 & $1,197.3 \pm 3,704.0$ & $2,752.5 \pm 2,000.4$ & 0.002 \\
\hline Day 5 & $1,236.0 \pm 4,634.1$ & $1,777.5 \pm 1,045.0$ & 0.002 \\
\hline Peak & $1,779.3 \pm 3,752.9$ & $2,679.4 \pm 3,448.2$ & 0.292 \\
\hline Red blood cell transfusion (U) & $3.0 \pm 3.3$ & $16.4 \pm 15.1$ & $<0.001$ \\
\hline Intensive care unit stay (d) & $3.5 \pm 7.1$ & $13.2 \pm 17.1$ & 0.002 \\
\hline Lactate $(\mathrm{mmol} / \mathrm{L})$ & $3.2 \pm 2.9$ & $9.2 \pm 7.1$ & 0.004 \\
\hline
\end{tabular}

Values are presented as mean \pm standard deviation or number (\%).

Table 4. Independent predictors for death in the multivariate logistic regression analysis

\begin{tabular}{lccr}
\hline & $\begin{array}{c}\text { Odds } \\
\text { ratio }\end{array}$ & $\begin{array}{c}95 \% \text { confidence } \\
\text { interval }\end{array}$ & p-value \\
\hline LnMG peak & 2.600 & $(1.038 \sim 6.517)$ & 0.041 \\
Acute kidney injury & 46.951 & $(0.445 \sim 4,948.395)$ & 0.105 \\
Age & 1.076 & $(0.973 \sim 1.189)$ & 0.152 \\
Lactate & 1.279 & $(1.076 \sim 1.520)$ & 0.005 \\
Packed red-blood cell & 1.422 & $(1.185 \sim 1.707)$ & $<0.001$ \\
$\quad$ trasfusion & & & \\
Injury Severity Score & 1.114 & $(0.938 \sim 1.322)$ & 0.219 \\
\hline
\end{tabular}

LnMG peak: $\log$ transformation of peak myoglobin value.

myocardical infarction, and myositis [7]. However, few studies have suggested myoglobin and $\mathrm{CK}$ as prognostic factors and researchers have reported somewhat different results. In addition, there are few reports related to trauma patients.

AKI is one of the most severe complications and, in particular, the percentage of cases after trauma varies from $1 \sim 31 \%$ [8,9]. The causes are an emergent operation, nephrotoxic drugs, low blood pressure, and hypothermia

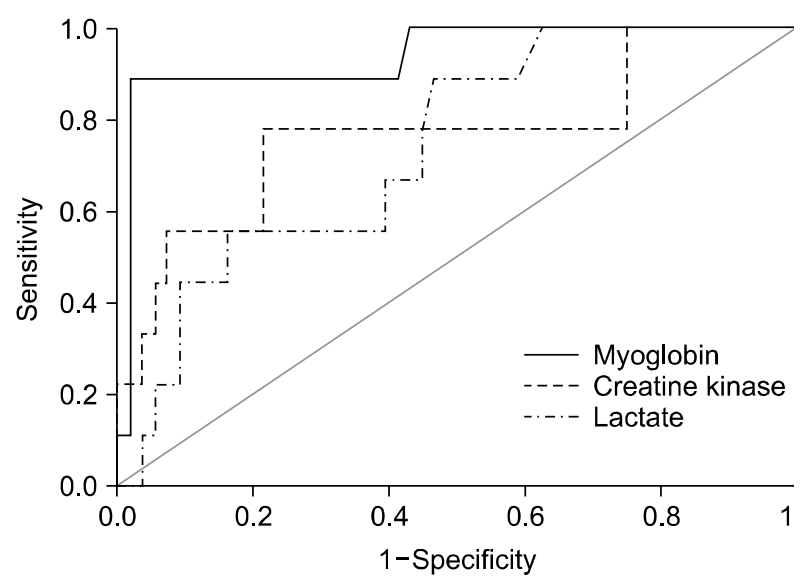

Fig. 1. Receiver operating characteristic curve for serum myoglobin, lactate, creatine kinase in predicting mortality.

$[10,11]$. Because of the influence of AKI over clinical course, to predict it is important thing for clinicians. Among many biochemical markers, $\mathrm{CK}$ and myoglobin were known to be higher than normal in rhabdomyolysis. In addition, they play important roles for developing renal damage [12]. Some researchers investigated the relation between their concentrations and AKI 
in rhabdomyolysis, and showed the various results. Melli et al. [13] showed a positive correlation between peak serum CK and serum creatinine. Kasaoka et al. [14] had failed to show the peak value of $\mathrm{CK}$ as a predictor of AKI, but they showed the peak blood levels of myoglobin in the AKI group are higher than the non-AKI group. In addition, they argued that the peak value of myoglobin might predict AKI. Similarly, in our study, myoglobin levels including the peak value were higher in the AKI group rather than the non-AKI group significantly, but CK were not shown that results. However, the results of CK on 5th and 7th day were significant statistically. Considering these results, CK might be influential factor for the prediction of AKI. As referred to earlier, predicting AKI is important. The clinicians will be possible to provide faster renal conservation treatment in the case of high-risk AKI by digitizing it. A study by Shiao et al. [15] reported that if renal replacement therapy was performed faster, prognoses would be better [16,17].

The factors related to the prognosis of trauma patients until now are vital signs during hospitalization, hypothermia, amount of blood loss, increased lactic acid by cyclic degradation and bleeding tendency by coagulopathy [18-20]. Many researchers have conducted studies on prognostic factors of trauma patients, but there are few direct studies about AKI and death in association with serum levels of myoglobin and CK. Myoglobin and CK have been known as useful clinical markers. They are thought to reach the circulation due to disruption of the cellular integrity, and cause systemic reactions depending on the extent and type of damage [12]. Theoretically, that is why we thought to myoglobin and $\mathrm{CK}$ as clinical markers making a prognosis.

As a result of comparing the surviving group of trauma patients with the non-surviving group in the present study, in the nonsurviving group, age, ISS, the length of ICU stay, and the serum lactic acid levels were higher. The serum myoglobin levels of all days in the surviving group were higher significantly. However, we failed to show CK differences between the surviving group and the non-surviving group like the former comparison. The results of CK on 3th, 5th and 7th day were only significant statistically. We presumed that because serum myoglobin peaked earlier than CK, the CK values were not different significantly on 1st and 2 nd day. Further studies will be needed.

Additionally, we perform the log-transformation of myoglobin levels because the difference between the maximum and minimum serum myoglobin values was too large and was not normally distributed. Table 4 shows the multiple logistic regression analysis about myoglobin peak levels as independent variables. In this analysis, the peak myoglobin levels were more influential than any other variables as a predictor of survival.

Lactate was known as a useful predictor for trauma mortality [21]. Interestingly, our ROC curves inferred that the value of myoglobin was superior [22] than the other factors for predicting mortality. So, we think that the myoglobin is worth a try for studying as a predictor of mortality. Our study indicates that the peak value of myoglobin can be a good indicator to predict death. Although effective treatment for damaged organs is important in trauma patients, it is very important to grasp the patient's overall status. Occasionally, a patient dies due to AKI or multiple organ dysfunction syndrome even if surgery or other interventions were successful. Survival rate may improve if the doctor realizes patients at high-risk for $\mathrm{AKI}$ and provides renal replacement therapy rapidly [13,22,23].

The limitation of this study was the small number of patients, especially, the number of enrolled patients in AKI and the mortality. It could create a selection bias. Additionally, due to the retrospective design, we had some missing data related the value of myoglobin and CK. So, we could not draw definitive conclusions. Although there were some limitations, the value of CK looks like it has relations with AKI, and the value of myoglobin seem to be related to AKI and the mortality.

Therefore, it is necessary to study more patient groups in a larger study and examine the correlation between the serum levels of myoglobin and $\mathrm{CK}$ as well as other factors.

Trauma patients had higher levels of serum myoglobin and $\mathrm{CK}$, and it appears that they are related to AKI. Of them, the serum level of myoglobin might be a good marker for predicting AKI and death. The results suggest that the value of increased serum myoglobin and CK in trauma patients might be useful 
for predicting the course of patients and planning the relevant treatments.

\section{References}

1. Weber MA, Kinscherf R, Krakowski-Roosen H, Aulmann M, Renk H, Künkele A, et al. Myoglobin plasma level related to muscle mass and fiber composition: a clinical marker of muscle wasting? J Mol Med (Berl) 2007;85:887-96.

2. Naka T, Jones D, Baldwin I, Fealy N, Bates S, Goehl H, et al. Myoglobin clearance by super high-flux hemofiltration in a case of severe rhabdomyolysis: a case report. Crit Care 2005;9:R90-5.

3. Lappalainen H, Tiula E, Uotila L, Mänttäri M. Elimination kinetics of myoglobin and creatine kinase in rhabdomyolysis: implications for follow-up. Crit Care Med 2002;30:2212-5.

4. Venkataraman R, Kellum JA. Defining acute renal failure: the RIFLE criteria. J Intensive Care Med 2007;22:187-93.

5. Li WX, Chen HD, Wang XW, Zhao S, Chen XK, Zheng Y, et al. Predictive value of RIFLE classification on prognosis of critically ill patients with acute kidney injury treated with continuous renal replacement therapy. Chin Med J (Engl) 2009;122:1020-5.

6. Sharp LS, Rozycki GS, Feliciano DV. Rhabdomyolysis and secondary renal failure in critically ill surgical patients. Am J Surg 2004;188:801-6.

7. Kodatsch I, Finsterer J, Stöllberger C. Serum creatine kinase elevation in a medical department. Acta Med Austriaca 2001; 28:11-5.

8. Beitland S, Moen H, Os I. Acute kidney injury with renal replacement therapy in trauma patients. Acta Anaesthesiol Scand 2010;54:833-40.

9. Brown CV, Dubose JJ, Hadjizacharia P, Yanar H, Salim A, Inaba $\mathrm{K}$, et al. Natural history and outcomes of renal failure after trauma. J Am Coll Surg 2008;206:426-31.

10. Srisawat N, Kellum JA. Acute kidney injury: definition, epidemiology, and outcome. Curr Opin Crit Care 2011;17:548-55.

11. Sear JW. Kidney dysfunction in the postoperative period. $\mathrm{Br}$ J Anaesth 2005;95:20-32.

12. Laurence AS. Serum myoglobin and creatine kinase following surgery. Br J Anaesth 2000;84:763-6.
13. Melli G, Chaudhry V, Cornblath DR. Rhabdomyolysis: an evaluation of 475 hospitalized patients. Medicine (Baltimore) 2005;84:377-85.

14. Kasaoka S, Todani M, Kaneko T, Kawamura Y, Oda Y, Tsuruta R, et al. Peak value of blood myoglobin predicts acute renal failure induced by rhabdomyolysis. J Crit Care 2010;25:601-4.

15. Shiao CC, Wu VC, Li WY, Lin YF, Hu FC, Young GH, et al; National Taiwan University Surgical Intensive Care Unit-Associated Renal Failure Study Group. Late initiation of renal replacement therapy is associated with worse outcomes in acute kidney injury after major abdominal surgery. Crit Care 2009;13:R171.

16. Seabra VF, Balk EM, Liangos O, Sosa MA, Cendoroglo M, Jaber BL. Timing of renal replacement therapy initiation in acute renal failure: a meta-analysis. Am J Kidney Dis 2008;52: 272-84.

17. Bagshaw SM, Uchino S, Bellomo R, Morimatsu H, Morgera S, Schetz M, et al; Beginning and Ending Supportive Therapy for the Kidney (BEST Kidney) Investigators. Timing of renal replacement therapy and clinical outcomes in critically ill patients with severe acute kidney injury. J Crit Care 2009;24: 129-40.

18. Zhou J, Kong D, Zhang X, Wang Y, Feng Z, Zhang X, et al. Myoglobin-induced apoptosis: two pathways related to endoplasmic reticulum stress. Ther Apher Dial 2012;16:272-80.

19. Hofmann D, Buettner M, Rissner F, Wahl M, Sakka SG. Prognostic value of serum myoglobin in patients after cardiac surgery. J Anesth 2007;21:304-10.

20. Bagley WH, Yang H, Shah KH. Rhabdomyolysis. Intern Emerg Med 2007;2:210-8.

21. Aslar AK, Kuzu MA, Elhan AH, Tanik A, Hengirmen S. Admission lactate level and the APACHE II score are the most useful predictors of prognosis following torso trauma. Injury 2004;35:746-52.

22. Oh HJ, Shin DH, Lee MJ, Koo HM, Doh FM, Kim HR, et al. Early initiation of continuous renal replacement therapy improves patient survival in severe progressive septic acute kidney injury. J Crit Care 2012;27:743.e9-18.

23. Chatzizisis YS, Misirli G, Hatzitolios AI, Giannoglou GD. The syndrome of rhabdomyolysis: complications and treatment. Eur J Intern Med 2008;19:568-74. 